\title{
Do Experiences Represent?
}

\author{
MICHAEL JACOVIDES
}

Purdue University, USA

\begin{abstract}
:
The paper contains four arguments to show that experiences don't represent. The first argument appeals to the fact that an experience can't occur without what the experience is of; the second appeals to the fact we can have an experience without having any awareness of what it is of, the third argument appeals to the fact that long experiences, such as the experience of being kidnapped, don't represent anything; and the fourth appeals to the fact that experiences often leave physical traces. The author rebuts several arguments for the conclusion that experiences represent. The author also considers some of the pitfalls involved in stipulating that 'experiences represent' in a technical sense of 'experience' or 'represent.'
\end{abstract}

\section{Disavowals}

Martin Davies writes for many, “A perceptual experience has representational properties; it presents the world as being a certain way" (310). ${ }^{1}$ I agree that the experience of attending an outdoor rock concert on a warm afternoon reveals a certain sunny, warm, and loud patch of the world, but I don't think that the experience represents anything. That is to say, I don't deny that we learn about the world from our experiences, but I do deny that they are internal mental proxies for external things. They aren't anything like newspapers, which allow us to contemplate states of affairs by signifying them. I have my doubts that there are any purely mental proxies in ordinary cases of sensation, but if there are, they aren't experiences. Correspondence Address: Michael Jacovides, Purdue University, Department of Philosophy, 100 N. University Street, West Lafayette, IN 47907, USA. E-mail: Jacovides@purdue.edu 
I also do not deny that seeing, hearing, and other sensory relations essential to almost all experiences take intentional objects. I endorse Anscombe's closely related semantic thesis that there are statements of perception in which the verb takes an intentional object, that is, is followed by an expression whose contribution to the truth conditions of the sentence is determined not by how the signified object is, but by how the signified object seems to be. I do deny that experiences are inner entities that represent those intentional objects.

I don't want to assert that nothing in the head represents external objects. I don't want to deny that some neural states represent externalities, or even that there are 'grandmother cells' that represent particular objects. ('Grandmother cell' was initially a term of derision intended to mock the supposition that individual neurons might represent individual people, but recent work has given the doctrine respectability. ${ }^{2}$ ) Whether there are, in fact, such neural states is a question for the neuroscientists, though philosophically minded cognitive scientists can do their part to move the inquiry along. Once such states have been securely established, philosophers might do useful conceptual work is explaining how such representational mechanisms are like and unlike those in other forms of representations. When that work has been done, or earlier, an enterprising philosopher might stipulate that such neural states are to be called 'experiences.' My thesis is that experiences, ordinarily so-called, do not represent anything.

In this I follow Crispin Sartwell (1995), Charles Travis (2004), William Alston (2005), and, from a previous era, John Dewey $\left(1929\right.$, Ch. 1). ${ }^{3}$ Sartwell's paper is the result of taking externalist doctrines in the philosophy of mind to their limits, Travis's is an application of J.L. Austin's teachings, and Alston's is part of his reworking of the "Theory of Appearing" developed by Harold Prichard, Dawes Hicks, and W.H. Barnes (Alston 1999, 201n1). My paper 
stems from the jarring sensation I received from reading recent analytic work on secondary qualities after reading Dewey.

\section{Representation by Stipulation}

Here are three ways in which 'experiences represent' might be made true by stipulation. First, it might conceivably be done while using the words 'experience' and 'represent' in their ordinary senses, second, it might be done by using a technical sense of 'represent,' and third, it might be done by using a technical sense of 'experience'.

The usual way in which things are stipulated to represent other things can't be used with experiences. As an example of this usual way, consider Fred Dretske's stipulations:

Let this dime on the table be Oscar Robertson, let this nickel (heads uppermost) be Kareem Abdul-Jabbar, and let this nickel (tails uppermost) be the opposing center. These pieces of popcorn are the other players, and this glass is the basket. With this bit of stage setting I can now, by moving coins and popcorn around on the table, represent the positions and movements of these players. I can use these objects to describe a basketball play I once witnessed (1988: 52-53).

This is a perfectly unproblematic way in which one thing can be stipulated to represent another, but it can hardly be how experiences represent states of affairs. The experience of learning to play the lute and the experience of looking at a tomato aren't public or manipulable in the way that coins and pieces of popcorn are. It would be futile and absurd to stipulate that George's experience of learning to play the lute should represent Oscar Robertson. So, if we stick to the

ordinary meanings of the relevant words, experiences can't be stipulated to represent basketball players, or, I think, anything else.

Setting ordinary meanings aside, we may assign a technical meaning to any word we choose, including 'represent' and 'experience'. Alan Millar writes, 
The content of an experience is the way it represents the world as being. But what is that? Let us say that an experience is such that it seems to the subject that $p$ if and only if in response to the experience the subject would believe that $p$ in the absence of countervailing considerations. If, in this sense, you have an experience such that it seems to you that $p$ then your experience has the content that $p$ (495).

Alex Byrne and David R. Hilbert (263) write that an experience "may be said to represent" the conjunction of each proposition that "looks to you as if" it is true while you're having the experience. ${ }^{4}$ I take it that Millar and Byrne and Hilbert are stipulating technical senses of 'represent' according to which experiences, ordinarily so-called, may be said to represent propositions. Notice that these are different stipulations. Millar's version has a clause about countervailing circumstances, and Byrne and Hilbert make experiences represent conjunctions. If some philosopher finds one of these stipulations helpful, I don't have any objection to it. We should be careful, however, to avoid three confusions that such stipulations may provoke.

First, we run the danger of confusing differences in stipulation for substantive disagreements. The differences between Millar's stipulation and Byrne and Hilbert's don't offer significant material for rational debate. In his survey of recent work on the 'representational character of experience,' David Chalmers recounts debates in the philosophical literature over what experiences represent (167-77). If the philosophers engaged in these controversies assign different technical meanings to 'represent,' then the debates are empty and pointless.

Second, and worse, such stipulations may push us into mistakes about the nature of experiences. Beliefs can be caused, at least in principle, by inner events, outer events, outer objects, or inner objects. Being in a situation also causes us to believe things. We might stipulate that a person's situation represents the conjunction of all the propositions that look true to a person in that situation just as easily as we might make that stipulation for experiences. No one supposes that experiences are exactly like inner paintings, but the Pickwickian sense of 
'represents' pushes us towards thinking of experiences as inner symbolic objects, since the central notion of representation is that of having one object stand for another. Experiences are more like situations than they are like paintings (Sartwell 69), and talk of the representational character of experience obscures that fact.

Third, stipulated senses of representation might mislead us into thinking that we understand the mechanism by which experiences generate beliefs. It's plain that experiences incline us to believe things. Paradigmatic representational objects, such maps, drawings, and epistles, also incline us to believe things. It does not follow that experiences incline us to believe things in the way that maps and drawings do. If we use the expression 'represents' to mean inclines us to believe, we run the danger of thinking that we have an explanation where we only have a form of words.

Beyond ordinary stipulations that one object represents another and stipulating a special sense to 'represents,' a third stipulative possibility is to assign a technical sense to the word 'experience.' According to Russell, "the word 'experience', like most of the words expressing fundamental ideas in philosophy, has been imported into the technical vocabulary from the language of daily life, and it retains some of the grime of its outdoor existence in spite of some scrubbing and brushing by impatient philosophers" (127-28). Though there may be no ordinary sense of 'experience' according to which experiences are representational, perhaps there's a technical sense of the word in accordance with which experiences do represent. No one should expect ordinary usage to tightly constrain technical terminology. Why should we get our concept of experience from experience, instead of from the pure realm of theory?

The ambitious might try to solve all disputes about the representational character of experiences in this way. In his survey, Chalmers first distinguishes pure, impure, weak, 
reductive, nonreductive, functionalist, narrow, and wide representationalisms. He goes on to distinguish physical, projectivist, primitivist, and dispositionalist varieties of Russellian representationalism and to distinguish these from Fregean representationalism. Someone in an irenic mood might stipulate that there are different concepts of experience for each doctrine and declare that the disputants are equally right and are merely talking past each other.

The first and obvious response to this procedure is that it merely multiplies concepts without telling us anything about how the world is. It isn't interesting to show that there can be a concept of an experience according to which experiences represent if there isn't any reason to believe that that concept is instantiated.

Russell's considered view in 1914 is that "the central ideal embodied in the word 'experience"" (129) is "a dual relation between a subject and an object which need not have any community of nature. The subject is 'mental', the object is not known to be mental except in introspection" (127). Russell contrasts his theory with "the theory that between subject and object there is a third entity, the 'content', which is mental, and is that thought or state of mind by means of which the subject apprehends the object" (ibid.). He criticizes various arguments for believing that experiences have contents and adds, "the chief argument against contents is the difficulty of discovering them introspectively" (173). The targeted notion of content isn't exactly the modern one, but Russell plainly doesn't think of experiences as psychic entities inside the subject and which represent external things. He is not a Russellian representationalist about experience, since he is not a representationalist about experience at all. Surely he is onto a substantive question about the structure of cognition, and he can't be refuted by mere stipulation. Many philosophers rejected the existence of sense-data for various reasons, but hardly anyone besides eliminativists has ever seriously questioned the existence of experiences. 
'Experiences happen' is a truism, but only if 'experiences' is taken in the ordinary sense. If a philosopher uses the word 'experience' as a referring technical expression, she owes her readers a definition and an existence proof. Presumably, for many definitions of 'experience' no successful proof can be made. Those who reject the existence of sense-data ought to consider whether similar arguments might apply against 'experiences', for each technical sense.

Second, we run the risk of conflating our intuitions about experiences in the ordinary sense with intuitions about experiences in the stipulated sense. Even if the only lesson that the reader takes away from this paper is that the word 'experience' is being used in a technical sense in recent philosophy, that still might be a stimulant for progress. I have no substantial complaint against jargon, but we ought to realize that it is jargon. Philosophers used to argue about 'sensedata.' That term was a fortunate one. Since it was no part of ordinary language, philosophers who contended for the existence of such things realized that they needed to lay the groundwork for their acceptance. Even those who thought that the existence of sense-data was obvious recognized that they needed to make a case for a particular conception of what they were. No one was tempted to appeal to 'what everyone knows' about sense-data.

In recent years sense-data have fallen by the wayside. Now philosophers talk about 'experiences'. But the modern debate is inferior to the older one in at least one respect. By using the word 'experience'--a term from ordinary language--philosophers have opened up the possibility of confusion. Philosophers may be using that notion in a technical sense, and yet because it is also part of ordinary thought, they may be tempted to assume that 'experiences exist' is a truism. Likewise, they may falsely appeal to 'what everyone knows' about experiences, even though there is nothing that everyone knows about the technical notion of an experience. Michael Thau complains about this sleight of hand: 
The way in which philosophers have hijacked the term experience to refer to alleged perceptual intermediaries makes the qualia freak's view seem as if it simply derives from common sense. After all, it is a matter of common sense that people have experiences. But, of course, it isn't at all a matter of common sense that people have experiences in the sense of the term that the qualia freak uses. It is not a matter of common sense that there are perceptual intermediaries, let alone that experiences are perceptual intermediaries (80, see also Byrne, §II.3).

People haven't much bothered to define technical senses of 'experience' or to contrast them with ordinary usage. Nor have they argued for the existence of the corresponding entity. Even those who aren't interested in experiences, ordinarily so-called, may still find my paper useful as a prod to definition, demarcation, and justification. ${ }^{5}$

\section{Four Arguments Against Thinking that Experiences Represent}

In my treatment, the canonical description of an experience will be "so-and-so's experience of $\phi$ " where $\phi$ is replaced by an expression for an event or a state and where so-and-so is the subject of the experience. Descriptions where $\phi$ is replaced with an expression for an ordinary object are, I think, elliptical for descriptions in my canonical form. Depending on context, 'Green's experience of a motorcycle' might mean Green's experience of owning a motorcycle, or Green's experience of riding a motorcycle, or Green's experience of sensing a motorcycle. If I am mistaken and there are descriptions of experiences of objects that can't be accurately paraphrased into descriptions of experiences of events or states, then my arguments won't apply to them. I'll sometimes describe the referent of an appropriate substitution for $\phi$ as a 'grounding event' or a 'grounding state.'

'Of' is said in many ways. In some expressions ('bust of Homer,' 'painting of Delft'), it denotes the relation between a representational object and the thing that it represents. We will be 
misled if we think that experiences represent their grounding events or states. I have four arguments to show that experiences don't represent.

Argument 1: From the Necessity of the Grounding Event or State

1. If experiences represent anything, they could occur without the occurrence of what they are of.

2. Experiences can't occur without the occurrence of what they are of.

So, 3. Experiences don't represent anything.

Experiences can't occur without their grounding events or states. We may see this by considering instances of apparent or actual mountain climbing. It is not possible to have the experience of climbing Mt. Everest without climbing Mt. Everest. If I am set down on the side of Mt. McKinley and told that it is Mt. Everest, I might believe that I have had the experience of climbing Mt. Everest, but I have not actually had that experience. Likewise, if I am put inside Robert Nozick's (42-45) Experience Machine, I haven't actually had the experience of climbing Mt. Everest, even though it might seem to me as if I had.

I could have an experience as of climbing Mt. Everest, both on Mt. McKinley and in the machine, but that is not same thing. ${ }^{6}$ In this context, 'as' is an adverb modifying the prepositional phrase 'of climbing Mt. Everest'. To have an experience as of climbing Mt. Everest is merely to have an experience that is like (that is, subjectively similar to) the genuine experience you get when you climb that very mountain. Truly having the experience requires being there.

According to William Lycan, it's "definitional of an intentional state that it is indifferent to actuality in Brentano's way: The state is and would be the state it is and have the intentional object it does regardless of whether the object actually exists" (6). On that definition of an intentional state, the experience of $\phi$ is not an intentional state with the intentional object $\phi$, since the experience can't occur without $\phi$. 
If experiences represented what they are of, then we would expect that they could occur independently of what they are of. Since they can't, we should conclude that they don't represent what they are of. More generally, I think, we can conclude that they don't represent anything. If experiences were inner mental proxies for external things, then they could occur no matter how things stand in the outside world. Since they can't, they aren't.'

In the course of arguing that experiences $d o$ represent, Dretske makes the following remark:

the properties we use to individuate experiences are the objective properties of the objects we experience, not the properties of the experiences themselves. We distinguish experiences not in terms of their properties, but in terms of the properties that their objects (if there are any) have. That sounds remarkably like a representational mode of classification, remarkably like the way we classify, say, stories and pictures. $A$ is a biography of Oscar Wilde, $B$ a history of the Spanish Civil War. We put these books on different library shelves not because they-the books - have such different properties, but because the they describe are so very different (2003: 72-73).

Dretske's remarks understate the extent to which experiences depend on their grounding states or events. Experiences require the occurrence of what they are of (again, as opposed to what they are 'as' of). This connection is too tight to be mere representation.

Dretske might reply that the 'of' in 'the experience of $\phi$ ' is the 'of' of successful representation. But when I mistakenly believe that I am climbing Mt. Everest while I am actually climbing Mt. McKinley, my experience of climbing Mt. McKinley does not successfully represent climbing Mt. McKinley. If it did, then I would have some inkling of where I was.

\section{Argument 2: From Absent Appearances}

1. If experiences represent what they are of, whenever a person undergoes an experience, it seems to that person that she's undergoing what the experience is of.

2. It sometimes doesn't seem to a person undergoing an experience that she's undergoing what the experience is of. 
So, 3. Experiences don't represent what they are of.

Suppose (as happens in the movie The Freshman) that White is deceived by being fed a mixture of turkey and tigerfish and told that it is meat from the last Komodo dragon. White has not had the experience of eating the last Komodo dragon; he just thinks he's had that experience. Unbeknownst to him, the experience that he has actually had is the experience of eating a mixture of turkey and tigerfish. The of in the experience of eating a mixture of turkey and tigerfish would not be the of of representation, since it doesn't seem to White that he's eating a mixture of turkey and tigerfish.

Deception isn't essential to the point. If a person eats a star fruit for the first time without being told what she is eating, she comes to have the experience of eating a star fruit, whether or not she ever discovers that fact. A person might have the experience of having mononucleosis without thinking that he's sick. Not knowing how things stand can hardly count as a countervailing circumstance in these cases.

There are cases, someone might object, where we are in the presence of a representational object, and we aren't inclined to believe whatever that object represents. ${ }^{8}$ This happens, for example, when we look at writing in an unknown language. Since that can happen with languages, perhaps it happens during an experience: the experience represents, but we aren't inclined to believe what it represents. Indeed, we don't know what it represents. Against this objection, we may observe that our state of mind when eating an unusual fruit isn't anything like our state of mind when we examine an unknown language. The experience doesn't seem to signify something to us that we don't understand, rather, we have a sense of discovery and newfound acquaintance. It isn't mysterious in the way that ancient undeciphered languages are mysterious. 


\section{Argument 3: From Long Experiences}

Someone else might reply that though experiences don't represent what they are of, they represent something else. We can see that they don't by considering long, drawn-out events.

1. Long experiences either represent their grounding events or states, an aggregate of what seems true at some time during the experience, or nothing at all.

2. Long experiences don't represent their grounding events or states.

3. Long experiences don't represent an aggregate of what seems true at some time during the experience.

4. If long experiences don't represent anything, then no experience represents anything. So, 5 No experience represents anything.

Patty Hearst's experience of being kidnapped by the SLA does not represent her being kidnapped by the SLA. Nor does Eisenhower's experience of planning to invade Normandy represent his planning to invade Normandy. No one, I think, will be inclined to say that they do.

If they don't represent their grounding states, then long experiences either represent an aggregate of what seemed to be true at some time during the experience or they represent nothing at all. I don't think long experiences can be reasonably thought to represent everything that seemed to be true during the experience. Given ordinary cognitive limitations, near the end of a long experience, most of what seemed true during the experience will be lost and forgotten. But the experience is still going on towards the end of the experience. At that time, it doesn't represent propositions that are utterly lost to the person who is having the experience.

Someone might say that experience represent whatever they incline us to believe, and thus that long events represent different things as they unfold. But, as the case of the undeciphered language shows, there's a difference between what something inclines us to believe and what that thing represents. We can call the property inclines us to believe 'representation,' but that doesn't make experiences represent, any more than calling the tail of a 
horse a 'leg' makes it one. Again, we can stipulate that words mean whatever we like. My point is merely that we ought not be bewitched by our stipulations.

So I conclude that long experiences don't represent anything at all. They are no more representational than kidnappings or invasions are representational. They may contain things that represent - external objects such as maps, utterances, and written descriptions as well as psychological entities such as mental imagery and internal dialogue. However, this is a tenuous and indirect sense of being representational. The invasion of Normandy included maps, commands, and descriptions, but we are not inclined to call the invasion a representation. ${ }^{9}$

If long experiences don't represent anything, then neither do short experiences, since there's no metaphysically significant place to draw a line between the two. Consider the experience of driving across country. Are we to imagine that it begins by representing various states of affairs, but then, somewhere around Barstow, it stops? There are, I concede, interesting psychological lines to be drawn between short and long experiences. We may inquire into the minimum time of an experience, the length of the specious present, or the line between short and long-term memory. None of these dividing lines, however, is a plausible candidate for the line between experiences that represent and those that do not.

The restriction of the expressions 'perceptual experience' and 'sense experience' to an especially banal subset of ordinary experiences covers up the homogeneity between brief and lasting experiences. The experience of seeing a red tomato stands in the same relation to seeing a red tomato as the experience of being kidnapped stands to being kidnapped. Since the second relation isn't representational, neither is the first.

Argument 4: From the Physical Traces of Experiences 
Here's a fourth argument for the conclusion that experiences don't represent. This argument won't convince anyone who wasn't convinced by the first three, but it is sound in my opinion. It also points the way to a proper positive account of experiences, something I won't attempt to offer here.

1. If experiences represent something, then they are purely internal mental events (either irreducibly psychic events or neural events under a guise).

2. If experiences are purely internal mental events, then they leave no immediate traces outside the brain.

3. Experiences leave immediate traces outside the brain

So, 4. Experiences don't represent anything

The experience of being beaten up can leave you resentful and bruised. The experience of vacationing in Barbados can leave you cheerful and tanned. Bruises and suntans are not the sorts of marks that inner mental objects could leave behind. Thus, the experience of being beaten up and the experience of vacationing in Barbados aren't inner mental objects. Thus, they don't represent. There's nothing extraordinary about those experiences, so we may generalize to the conclusion that experiences don't represent.

If bicycling across the country is good for your health, then the experience of bicycling across the country is good for your health. Someone might object that we only say such things, but we don't really mean them. After all, dreaming that you've bicycled across the country doesn't improve your health. Yes, but the experience of dreaming that you're riding a bicycle is quite different (subjectively and objectively) from the experience of riding a bicycle. The fact that dreamers sometimes confuse the two only shows how gullible we are when we are asleep.

The subjective difference between dreams and waking experiences is one that Austin emphasized (48-50). I would emphasize the objective difference (as does Sartwell 66-67). Even if philosophers arrange for a man in a coma to dream vividly that he's riding across the country and the dream has no trace of any dreamlike quality, the comatose man doesn't have the 
experience of riding a bicycle across the country nor does he receive the health benefits of that experience.

\section{Rebuttal to Arguments that Experiences Represent}

Let me turn to criticizing arguments for the thesis that experiences do represent. Gilbert Harman argues,

Our experience of the world has content - that is, it represents things as being in a certain way. In particular, perceptual experience represents a perceiver as in a particular environment, for example, as facing a tree with brown bark and green leaves fluttering in a slight breeze. One thing that philosophers mean when they refer to this as the intentional content of experience is that the content of the experience may not reflect what is really there. Although it looks to me as if I am seeing a tree, that may be a clever illusion produced with tilted mirrors and painted backdrops. Or it may be a hallucination produced by a drug in my coffee (34).

There is, I say, a gap between premise and conclusion. The examples Harman cites shows that sight takes intentional objects, but his conclusion is that experiences represent those intentional objects.

According to Christopher Peacocke, "a man may be familiar with a perfect trompe l'ail violin painted on a door, and be sure from his past experience that it is a trompe l'cil: nevertheless his experience may continue to represent a violin as hanging on the door in front of him" (6). It's fine to say that the painting looks like a violin. There's even a sense, I believe, in which the man may be said to see a violin, even if there isn't a violin there, and even if he knows that there isn't a violin there. That is, using Anscombe's terminology, the intentional object of the man's sight might be a violin, even if the material object of sight is paint on a door, and this can be so even if the man knows that the material object is just paint. 
Peacocke, however, uses the example to draw a distinction between the "representational content of an experience" with the "sensational properties" of that experience (5). This seems misguided to me. One can believe that things appear a certain way without positing inner experiences that represent the appearances (Byrne 2009 §III). In Peacocke's example it looks like there's a violin on the door even though there isn't. In other words, the intentional and material objects of sight differ. It doesn't follow that the man's experience represents that intentional object, or that his experience stands to that object as signifier to signified. Future neuroscientists may discover groups of neurons that represent apparent violins in such cases, but that would be a scientific discovery and not anything that follows from logical analysis or phenomenology.

A similar movement from intentional object to representation occurs in an argument that Dretske offers "in favor of a representational account of perceptual experience" (2003: 73). He asks,

What is it one sees (experiences) when hallucinating a pink rat? Certainly not a pink rat-everyone agrees about that - but is it, nonetheless, something that, like a pink rat, is pink and rat-shaped? Is it something that exemplifies these properties? There certainly seems to be something, but, if there is, where is this pink, rat-shaped, thing? It isn't out there. Just ask your friends (ibid.).

In one sense of 'what one sees,' the victim of the hallucination sees a pink rat. In another sense, he sees nothing. To put it another way, the intentional object of sight in the example is a pink rat and there is no corresponding material object.

According to Dretske, "a representational theory provides a happy rescue" to the difficulties involved in answering his questions:

In hallucinating pink rats we are aware of something - the properties, pink and rat-shaped that something represented as having - but we are not aware of any object that has these properties - a pink, rat-shaped, object. We are aware of pure universals, uninstatiated properties. A representation, remember, doesn't need an 
object that has the properties the represents something to have. . . Just as radar can 'hallucinate' an airplane approaching from the east at 35,000 feet, a visual experience can represent a pink rat in the corner without there being anything certainly nothing pink and rat-shaped - it represents to be that way. There does not have to be anything $\mathrm{X}$ represents to have the property $\mathrm{Y}$ for $\mathrm{X}$ to represent there to be something having the property Y. Problem solved (ibid.).

Dretske's initial care in describing what is represented as a conjunction of the universals pink and rat-shaped is a red herring. If inner representations can represent <pink, rat-shaped $>$, then they can represent a pink rat.

Dretske's considered answer to his initial question is, I think, that there seems to be a pink rat in the corner, but there isn't actually anything out there. That's indisputable, and one of Anscombe's contributions was to offer perspicuous terminology for making that indisputable answer. Dretske goes beyond Anscombe in offering an explanation of how the hallucinator comes to have the intentional object he has: in virtue of an inner entity that represents that intentional object.

Are there any inner entities that represent intentional objects? I don't think neuroscience has decisively concluded that there's a neural state corresponding to every intentional object or that there are neural states that represent hallucinated objects. But if we construe Dretske's argument as an inference to the best explanation for the conclusion that there are probably inner representational entities, I think that it has the backing of our best current science. Nevertheless, the argument doesn't show that experiences, ordinarily so-called, represent anything. ${ }^{10}$

Another argument Dretske offers runs as follows:

I don't know of any other theory about the nature of sense experience that tells this satisfying a story about first vs. third person aspects of experience. If we agree that experiences of orange pumpkins exist in the brain of the person seeing the pumpkins, why can't other people tell what these experiences are like by looking in the brain, at the experiences, of the person having them? For the same reason I can't tell what story is being told by looking inside a book written in Chinese. It may, for all I can tell, be about coaches turning into pumpkins. I see 
the representations clearly enough, but, with no understanding of the code (in this case, the language), I fail to understand their meaning (content). Unless you know the language, you can't identify representational content by looking at the objects (vehicles) that have it (2003: 71).

I would deny that experiences are inside the skull, ${ }^{11}$ but even on Dretske's own assumptions the analogy is dubious. Two pages later, he writes, "seeing a tree is not to be understood as awareness of some mental intermediary (an image, a sense-datum) having the properties the tree appears to have." Surely he doesn't think that seeing should be understood as the awareness of some neural intermediary. People can't see the insides of their brains. If someone showed Dretske a detailed photograph of his brain, he wouldn't be able to use his hypothesized knowledge of his own brain code to tell what he was thinking of at the time of the photograph. Whatever his relation to his neural states is, it isn't like the relation of a Chinese person to the pages of a book written in Chinese.

I now turn to some arguments not intended to show immediately that experiences represent, but which would entail that they do, if the arguments were sound. One of the best sources for such arguments is Michael Pendlebury's “Sense Experiences and their Contents: a Defence of the Propositional Account". Pendlebury argues for the narrower thesis that experiences represent propositions. If any of these arguments succeeded, it would follow that I am mistaken and experiences are representational events.

Pendlebury first argues (224-25) that sense experience must represent propositions on the grounds that otherwise we could not make sense of sensible judgments such as "these sense experiences support (or: do not support) this belief" and "these sense experiences are consistent (or: inconsistent) with those beliefs." If this were a good argument, then it would show that Col. Mustard's holding a smoking gun represents a proposition, since, after all, it supports that belief that Mustard is a murderer. 
One might reply that only a belief or something like a belief can justify a belief. This is, I think, a confusion. If anything can justify a belief, it's evidence. Beliefs may count as evidence in certain special circumstances. For example, a sociologist may test a hypothesis by surveying her subjects about their beliefs. The beliefs of the subjects (though not, of course, the beliefs of the sociologist) may rightly and narrowly be said to be evidence for or against that hypothesis. Even so, the appeals to beliefs as evidence that sociologists, anthropologists, and psychologists make aren't common in other sciences or in everyday life.

Beliefs aren't paradigmatic examples of evidence. Fingerprints, the results of a blood test, and black balls drawn from an urn are. It's true, perhaps, none of those things would count as evidence if they weren't believed to be evidence. ${ }^{12}$ The important thing is that they themselves--the smudge on the window, the negative result for hepatitis, and the three black balls drawn in a row--may all properly be said to support various beliefs, and none of them is a mental representation. Jerry Fodor has excellent things to say on this subject:

the data for a theory are just whatever confirms its predictions, and can thus be practically anything at all (including, by the way, bits and pieces of other theories). So, the data for big bang cosmology include "observations" of the cosmic microwave radiation background; the data for Mendelian genetics include the "observed" ratios of traits in the offspring of heterozygotes; the data for the gene theory include Mendel's "observation" (i.e. they include the Mendelian law) that heterozygotes breed true; the data for parsing theories include "observed" asymmetries of reaction times between subjects listening to sentences of related syntactic types. And so on. These uses of "observe" and its cognates have pretty clearly come unstuck from "seeing as" or, indeed, from anything that's psychological (208).

Such data direct us to the truth without thereby representing a truth, or anything else, for that matter. Just so, an experience may lead its possessor to the truth without representing anything. ${ }^{13}$ Pendlebury (224) thinks that it is important that philosophers call experiences 'veridical' and 'non-veridical' and concludes that this means that experiences can be true or false. But 
experiences cannot be true or false, not really. ${ }^{14}$ If calling experiences 'veridical' and 'nonveridical' means anything, it means that they incline us to believe true propositions or false propositions. The terminology is misleading insofar as it suggests that there is a single proposition associated with each experience. If my experience of attending a meeting inclines me to falsely believe that Plum is a snappy dresser and to truly believe that those donuts were delicious, should the experience be called veridical or non-veridical?

Later, Pendlebury (225) concludes that experiences represent propositions from the fact that "Philosophers of Perception and Epistemologists take for granted . . . that sense experiences are the sorts of things which can be accepted and rejected." This also seems to be a misleading way of talking. Suppose I watch a magician appear to saw a woman in half. I don't want to reject my experience of watching the trick. I may have paid good money to see that trick. Rather, I want to reject the belief that the experience inclines me to have, the belief that the magician is actually sawing a woman in half. Experiences incline us to accept beliefs without thereby representing those beliefs.

Even if all is well with the technical notion of experience, what people usually call experiences are philosophically interesting events. Such events deserve reflection. The fact that we might stipulate that something else be called an 'experience' shouldn't distract us from that reflection. Experiences ordinarily so-called are the pieces into which we carve up our days. They are sources of memory, wisdom, and happiness. And they do not represent anything.

\section{Bibliography}

Alston, W. (1999) "Back to the Theory of Appearing”, Philosophical Perspectives, 33, pp. 181203. 
-----. (2005) "Perception and Representation", Philosophy and Phenomenological Research, 70, pp. 253-89.

Anscombe, G.E.M. (1981) “The Intentionality of Sensation: A Grammatical Feature”, in: Metaphysics and the Philosophy of Mind, Collected Philosophical Papers, vol. 3, pp. 320 (Minneapolis: University of Minnesota Press).

Austin, J. L. (1962) Sense and Sensibilia (Oxford: Oxford University Press).

Byrne, A. (2009) "Experience and Content", The Philosophical Quarterly [article online in advance of print].

Byrne, A. and D. R. Hilbert (1997). “Colors and Reflectances”, in: A. Byrne and D. R. Hilbert (Eds.), Readings on Color, vol. 2. pp. 263-88 (Cambridge, Mass.: The MIT Press).

Campbell, J. (2002) Reference and Consciousness (Oxford: Clarendon Press).

Chalmers, D. (2004) “The Representational Character of Experience”, in: B. Leiter (Ed.), The Future for Philosophy, pp. 153-81 (Oxford: Clarendon Press).

Connor, C.E. (2005) “Friends and Grandmothers”, Nature, 435, pp. 1036-37.

Davies, M. (1997) “Externalism and Experience”, in: N. Block, O. Flanagan, and G. Güzeldere (Eds.), The Nature of Consciousness: Philosophical Debates (Cambridge, Mass.: The MIT Press).

Dewey, J. (1929) Experience and Nature, $2^{\text {nd }}$ ed. (LaSalle, Illinois: Open Court).

Dretske, F. (1988) Explaining Behavior: Reasons in a World of Causes (Cambridge, Mass.: The MIT Press).

----- (2003) “Experience as Representation”, Philosophical Issues, 13, pp. 67-82.

Fodor, J. A. (1991) “The Dogma that Didn't Bark (A Fragment of a Naturalized Epistemology)”, Mind, 100, pp. 201-20. 
Harman, G. (1990) “The Intrinsic Quality of Experience”, Philosophical Perspectives, 4, pp. 3152.

Lycan, W.G. (2006) "Enactive Intentionality", Psyche, 12.

Millar, A. (1991) “Concepts, Experience, and Inference”, Mind, 100, pp. 495-505.

Nozick, R. (1974) Anarchy, State, and Utopia (New York: Basic Books).

Peacocke, C. (1983) Sense and Content: Experience, Thought, and their Relations (Oxford: Clarendon Press).

Pendlebury, M. (1990) "Sense Experiences and their Contents: a Defence of the Propositional Account", Inquiry, 33, pp. 215-30.

Quiroga, R.Q., L. Reddy, G. Kreiman, C. Koch, and I. Fried. (2005) “Invariant Visual Representation by Single Neurons in the Human Brain”, Nature 435, pp. 1102-1107.

Russell, B. (1956) “On the Nature of Acquaintance.” in: R. C. Marsh (Ed.), Logic and Knowledge (London: Routledge).

Sartwell, C. (1995) "Radical Externalism Concerning Experience”, Philosophical Studies, 78, pp. 55-70.

Thau, M. (2002) Consciousness and Cognition (Oxford: Oxford University Press).

Travis, C. (2004) “The Silence of the Senses”, Mind, 113, pp. 57-94.

Valberg, J. J. (1992) The Puzzle of Experience (Oxford: Clarendon Press).

${ }^{1}$ I presented some of this material at the 2003 Pacific APA with Bernard Kobes commenting. I'm grateful to Kobes and to various audience members for their questions and comments. I received detailed, useful comments on drafts from Jeff Brower, Dave Chalmers, Simon Evnine, 
Amy Kind, Chris Pincock, Alex Rajczi, and many referees. I've had helpful conversations on the subject with many people, including Rogers Albritton, Jan Cover, and Gary Matthews. ${ }^{2}$ Quiroga et al.: 2005, discussed by Connor (2005).

${ }^{3}$ J.M. Hinton distinguished an ordinary notion of experience from the philosophers' special notion of experience. According to Hinton, experiences in the ordinary sense should be identified with what they are of: "The experience, (of) $X$-ing, in this sense, is no other event or think than $X$-ing, the event of which one is the grammatical subject" (6). Hinton denies that anything instantiates the philosophers' notion of experience, since there's no inner event common to the perception of an object and the illusion of perceiving that object ( $\S I \mathrm{Ib})$. Since no one would say that swimming the Bosphorus or other such events represent anything in the relevant sense of representation, he counts as someone who denies that experiences represent. In 'Experience and Content' (2009 §II.2), Alex Byrne accepts Hinton’s analysis of experiences, ordinarily so-called, and thus he also counts as someone who denies that such events represent. Bertrand Russell (1956) and John Campbell (2002 chs. 6-7) also don't think of experiences as representational proxies.

${ }^{4}$ This is no longer Byrne's favored analysis. See note 3 and Byrne 2009..

${ }^{5}$ The previous two paragraphs are heavily indebted to Alex Rajczi, though he didn't have anything to do with the reference to Thau.

${ }^{6}$ See J.J. Valberg 72-74. Valberg's subsequent discussion does not undermine the basic point, or, if it does, I don't see how it does.

${ }^{7}$ According to a referee, "This is a good argument, except that there are uses of 'represent' for which it is not. (And it's worth saying this.) E.g., 'This motorcycle represents years of penny- 
pinching, and boring evenings at home rather than down the pub', or 'Gavin is representing Sara (in this dispute)'. It's also not perfectly clear that a piece of popcorn could represent Charles Barkley but for Charles Barkley." True enough, but I don’t think that anyone thinks that experiences represent in any of these senses of 'represent'.

${ }^{8}$ This is a point that I owe to Amy Kind.

${ }^{9} \mathrm{I}$ am indebted to Gary Matthews for the objection.

${ }^{10}$ Along the same lines, William Lycan has criticized Alva Noë's thesis "that visual experiences do not per se represent at all, at any level" (6). I myself believe that experiences do not represent at all, either per se or per alio, so one might think I should reply to Lycan's arguments. But when he turns to actually offering arguments against Noë's position, he argues for relatively mild position that "vision represents or is at least intentional," and his arguments only show that sight takes intentional objects (7). I grant that neural states in the visual cortex may be said to represent external objects, in a strict and careful sense of 'represent,' and I grant that perception takes intentional objects. I want to deny only that experiences represent those intentional objects. Peacocke, Harman, Dretske, and Lycan's premises don't imply that they do.

${ }^{11}$ For accounts of how this might be, see Dewey, Hinton, or Sartwell.

${ }^{12}$ A referee protests my conciliatory tone: "Why admit this? It's just a shame that, for years, people just wouldn't believe the evidence that smoking causes cancer. Human beings (and tobacco companies) being what they are, it's hardly inconceivable that people still wouldn't believe this overwhelming evidence. People are liable to be like that. For all of which it would still be evidence. The status of evidence has to do with bearing, and is not a psychological 
matter." Indeed, there's such a thing as objective evidence, which is evidence regardless of whether anyone acknowledges it as such.

${ }^{13}$ For an attempt to fill in some details of how this could work, see Alston, 277.

${ }^{14}$ They might be authentic or inauthentic, but this isn't what Pendlebury has in mind. An experience is authentic if it is close to a prototypical or initial experience. For example, the experience of eating a taco at Taco Bell doesn't count as authentic, since it isn't close to the prototypical taco-eating experience. The experience of hearing the Brandenburg Concerto played with a harpsichord is more authentic than that of hearing the same piece on a piano. 